\title{
O PENSAMENTO TECNOCRÁTICO E AUTORITÁRIO NA EDUCAÇÃO BRASILEIRA, de 1964 a 1985
}

\author{
Maria José Aviz do Rosário ${ }^{1}$ \\ Universidade Federal do Pará - UFPA
}

\section{RESUMO}

O presente texto reúne indicações para discussão e análise dos fundamentos acerca do pensamento tecnocrático e autoritário implementado na educação brasileira pelo governo dos militares entre 1964 e 1985, tendo por base as Reformas de ensino, Lei 5.540/68 e 5.692/71 que reformaram respectivamente os níveis de ensino superior e primário e secundário e - contribuir para o debate sobre o pensamento pedagógico brasileiro; para a pesquisa educacional e; reflexão das atuais reformas educacionais em curso no país. Articula-se a tese de que a política educacional dos governos militares cuja base foram as reformas de ensino serviram para auxiliar a internacionalização da economia mantendo com isso, o país na periferia do capitalismo mundial. Para compreender os fundamentos do pensamento tecnocrático e autoritário implementado na educação brasileira, a partir do golpe militar de 1964 - 1985 e responder os objetivos propostos desenvolveu-se um estudo baseado nos procedimentos de: 1) pesquisa bibliográfica e, 2) análise documental. Em relação a pesquisa bibliográfica foram reunidos dados que pudessem recompor o quadro contextual das reformas de ensino, lei 5.540/68 e 5.692/71 e em seguida partiu-se para a análise dos documentos procurando "dar voz a documentação " e a mesmo tempo "escutar a voz da documentação", que no caso em questão foram as leis 5.540/68 e 5.692/71. Sua estruturação apresenta elementos que compõem a justificativa na qual evidencia - se o problema pesquisado que tematizou os fundamentos do pensamento tecnocrático e autoritário durante o governo dos militares, enfocando as reformas de ensino, lei 5.540/68 e 5.692/71, haja vista que o país passava por um processo de redirecionamento político/social no qual os militares a serviço dos capitais nacional e internacional, das classes dominantes e seus privilégios, assumiram como atores principais o papel de combate às forças civis e políticas de esquerda, progressistas e democráticas que atuavam de modo organizado no país. Deste modo, foi instalado a linha de ação numa perspectiva civil/político/militar, baseada na tecnocracia e autoritaritarismo em todas as instituições sociais, tendo em vista o princípio norteador principal da política - segurança e desenvolvimento nacional.

Palavras-chave: Educação brasileira; Reformas de ensino, ditadura militar; Lei 5.540/68 e 5.692/71; tecnocracia e autoritaritarismo

\section{ABSTRACT}

The present text gathers indications for discussion and analysis of the fundamentals about the technocratic and authoritarian thought implemented in Brazilian education by the military government between 1964 and 1985, based on the Reforms of teaching, Law $5,540 / 68$ and 5,692/71, which respectively reformed the levels of higher education and primary and secondary education, and - contribute to the debate on Brazilian pedagogical thinking; For educational research and; current educational reforms in the country. It is articulated the thesis that the educational policy of the military governments whose base was the educational reforms served to help the internationalization of the economy, thereby keeping the country on the periphery of world capitalism. In order to understand the fundamentals of technocratic and authoritarian thought implemented in Brazilian education, from the military coup of 1964 to 1985 and to answer the proposed objectives a 
study was developed based on the procedures of: 1) bibliographic research and 2) documentary analysis. In relation to the bibliographic research, data were gathered that could recompose the contextual framework of the educational reforms, Law 5,540 / 68 and 5,692 / 71, and then went to analyze the documents seeking to "give voice to documentation" and at the same time " Listen to the voice of documentation ", which in the case in question were laws 5,540 / 68 and 5,692 / 71. Its structure presents elements that make up the justification in which it is evident the researchedproblemthatthematicalizedthefoundationsof the technocratic and authoritarian thought during the military 's government, focusing on the reforms of education, Law $5.540 / 68$ and $5.692 / 71$, since the Political and social redirection in which the military in the service of the national and international capitals of the ruling classes and their privileges assumed the role of fighting against the progressive and democratic left civilian and political forces that acted Organized in the country. In this way, the line of action was set up from a civil / political / military perspective, based on technocracy and authoritarianism in all social institutions, in view of the main guiding principle of security - security and national development.

Keywords: Brazilian education; Educational reforms; Military dictatorship; Law 5.540/68 and Law 5.692/71; Technocracy and authoritarianism

Em 1964 o Brasil foi assaltado pelo golpe militar e, passado mais de meio século, sua repercussão ainda é grande, suas marcas ainda são fundas e as consequências à história do pensamento educacional são visíveis e objeto de investigação no sentido de compreensão de seu significado ao país e América Latina. „Controlando com mão de ferro, pelo exercício do poder político, o conjunto da sociedade brasileira ao longo de duas décadas, regime militar deixou um oneroso legado cujos efeitos continuam afetando a situação social do país nos dias de hoje $e^{\text {ee }}$ (SAVIANI, 2008, p. 294).

Este texto reúne indicações para discussão e análise dos fundamentos acerca do pensamento tecnocrático e autoritário implementados na educação brasileira pelo governo dos militares entre 1964 e 1985, tendo por base as Reformas de ensino, Lei 5.540/68 e 5.692/71; foi escrito e apresentado, em 2004, em um congresso internacional de educação ${ }^{2}$ e, portanto aquela altura o texto tinha como objetivo apresentar os resultados de pesquisas realizados para a feitura de uma tese de doutoramento e relatório de pesquisa CNPQ. De lá para cá, foram acumuladas à ideia inicial, outras discussões frutos de debates nas aulas de graduação e pós-graduação, bem como de orientações de TCC e dissertações de pesquisa, inseridas devidamente ao presente texto.

A instigação de publicação deve - se basicamente a dois fatores, às solicitações para uso científico, nos curso de graduação e pós-graduação e a aprovação pelo HISTEDBR - Secção-PA, em 2014, no edital universal - cnpq, do projeto, "Form(ação) de Professoras/es em tempos de ditadura: o Instituto de Educação do Pará no período de 1964 a 1985". A aprovação aumentou o desejo de compartilhar as reflexões acumuladas sobre a educação no período da ditadura.

O cenário no qual foi montada e desenvolvida a política educacional durante o regime militar, de 1964 - 1985 permite pensar que a educação formal foi um instrumento importante de veiculação, divulgação e consolidação do ideário autocrático e autoritário que permeou todo período deixando a sua marca na história do pensamento educacional e instituições escolares. 
Ao assumirem o poder político do país, os militares orientaram-se segundo o binômio "desenvolvimento e segurança nacional", usando como pano de fundo a proposta de livrar o país da corrupção, do comunismo e para restaurar a democracia. Sobre a Doutrina de Segurança Nacional, Gaspari, (2002, p 39) analisa que,

Para explicar a brutalização da política, recorreu-se demais ao que se chama de Doutrina de Segurança Nacional ou, na sua denominação crítica, Ideologia de Segurança Nacional. Trata-se de um sistema através do qual se teria processado, calculadamente, a articulação da ditadura.

O caráter autoritário permeava a ação do governo dos militares, 'a figurado chefe do governo se confundia com a de representante da vontade militar, tornando-se ora seu delegado, ora seu prisioneiro' (GASPARI, 2002, p. 35). Tal caráter mostra-se com nitidez, quando foi instituído o Ato Institucional I, de abril de 1964.

Modifica a Constituição do Brasil de 1946 quanto à eleição, ao mandato e aos poderes do Presidente da República; confere aos Comandantes-emchefe das Forças Armadas o poder de suspender direitos políticos e cassar mandatos legislativos, excluída a apreciação judicial desses atos; e dá outras providências" http://www4.planalto.gov.br/legislacao/legislacaohistorica/atos-institucionais.

Além da mudança ao arcabouço jurídico normativo, por meio dos atos adicionais, a ditadura promoveu ações repressivas, por meio da implementação da tortura, nas suas mais diversas naturezas, emocional, física e moral, pois 'existiu uma identidade, uma relação e um conflito entre o regime instalado em 1964 e a manifestação mais crua da essência repressiva que o Estado assumiu na sua obsessão desmobilizadora da sociedade: a tortura' (GASPARI, 2002, p. 129)

Ao analisar esse período, pela ótica da juventude, Syrkis (1980, p.128), não deixa dúvidas das atrocidades cometidas em nome da "democracia" e da ordem, no Brasil pós 1964.

Mas que as técnicas de suplício reveladas nos seus detalhes: choques elétricos, afogamentos, pau de arara, etc., o que chocava o sadismo, a maldade imensurável, a degradação humana. O objetivo fundamental da tortura era destruir a personalidade do preso, triturar a sua condição de ser humano, humilhá-lo nos cantos mais recônditos do seu ego, violentar as suas mais ocultas fraquezas. Era executada e cientificamente aperfeiçoada por seres totalmente deformados, imbuídos de uma mentalidade nazista. Adoravam fazer aquilo e tinham todo o tempo.

Em sua perspectiva mais ampla, a ditadura militar foi decorrência de uma profunda divisão da sociedade brasileira, que tinha como horizontes de expectativa projetos distintos para a condução política do país, uma parte como a juventude universitária acreditava que era impossível o desenvolvimento do país sem democracia e reformas sociais e outra apostava na modernização de forma autoritária e autocrática. A ditadura inserida nesta última usou como forma de "convecimento" o autoritarismo e a repressão, eliminando a força todos/as que discordam de seus encaminhamentos político-ideológicos, não deixava abertura ao contraditório. O golpe usado como solução política imposta pela força, ao 
derrotar as forças democráticas, nacionais e populares, significou a derrotou também uma alternativa de desenvolvimento econômico - social e político (NETO, 2014).

O "sucesso" do golpe pode ser debitado, em parte, ao governo de Jango. Este não conseguia atender aos anseios da sociedade brasileira e nem deslanchar as reformas de base; aumentou as inquietações de setores sociais, particularmente da burguesia conservadora, oferecendo, deste modo, elementos para uma 'operação civil- político militar destinada a limpar o terreno para a execução mais ampla e eficaz - isto é, ortodoxa - do modelo internacionalista.' (Ianni, 1988: 110).

As contradições no interior da sociedade, particularmente, a partir dos anos 50, aumentaram muito. Pode-se observar que no cenário político/social, ideologicamente o clima era o nacional desenvolvimentismo (dessa expectativa comungava o próprio governo com suas instituições, a exemplo do ISEB), as esquerdas, a igreja, os partidos políticos e ideológicos; economicamente, o clima era outro, a opção foi pela abertura ao investimento estrangeiro.

O processo passa a ser apresentado a partir de 1945, com o fim do período convencionado de Estado Novo, até 1964, com o golpe militar, o país passou por um processo de mudança permeado por relações sociais complexas em todas as instituições sociais, no qual as contradições de forças sociais se apresentaram com bastante nitidez. Nesse período ${ }^{3}$ observa-se a chegada ao poder do Marechal Dutra, colocando em 1947, o Partido Comunista, na ilegalidade; um período de crescimento com o Plano de Metas, de JK, a volta e a morte de Getúlio Vargas; a vitória acachapante de Jânio Quadros e seus seis meses de governabilidade, até sua renuncia e por fim o governo de Jango e sua proposta de Reformas de Base.

Ressalta-se que nesse período havia o desejo de importantes segmentos sociais, como os intelectuais, os partidos alinhados à esquerda, os estudantes, os sindicatos, entre outros, de (re)construção democrática das instituições sociais em cuja base encontram-se o período nacional-desenvolvimentista e o modelo político, calcado na democracia liberal pós Estado Novo com "a ascensão de outras facções da classe dominante ao poder, verificando-se a recomposição das forças políticas e econômicas" (IANNI, 1988, p. 18).

Ainda que as mudanças fossem operadas apenas no plano das estruturas sociais, havia segmentos sociais organizados que alimentava o desejo de se mudar a face do Estado brasileiro. Nesse quadro, observa-se a semelhança com a denominação gramisciana de revolução passiva (momento da renovação) quando as frações dominantes são obrigadas a fazer concessões para se manterem no poder político. Coutinho (2003, p. 198), ao discutir o conceito de revolução passiva, anuncia as suas características principais. .

[...] algumas características que o conceito de "revolução passiva" apresenta em Gramsci. Deve-se sublinhar, antes de mais nada, que um processo de revolução passiva, ao contrário de uma revolução popular, realizada a partir "de baixo", jacobina, implica sempre a presença de dois momentos: o da "restauração" (na medida em que é uma reação à possibilidade de uma transformação efetiva e radical "de baixo para cima") e o da "renovação" (na medida em que muitas demandas populares são assimiladas e postas em prática pelas velhas camadas dominantes. 
O Estado, nesse contexto, aparecia como o principal mediador dos interesses inconciliáveis das forças sociais. Porém, em alguns momentos, foi obrigado pelas contradições a mostrar sua face verdadeira de defensor dos interesses e regalias históricas da classe dominante. Essa contradição que indicava os diversos tipos de compromissos de classe, no seio do próprio Estado, ficou bem visível quando da cassação do registro do PCB, em 1947.

Esse episódio mostra que as forças sociais que compunham o poder dominante resolveram que as "liberdades" propugnadas por elas não admitiam a presença de outras forças sociais com concepções diferentes de encaminhamento das demandas requeridas pelo conjunto da sociedade, como era o caso do PCB.

Pode-se denotar a tônica, da década de 1950 e início da de 1960, era essa aliada à construção do parque industrial baseado no capital monopolista estatal e multinacional, logo, a bases econômicas iam de encontro com a ideologia apregoada: nacional desenvolvimentista. ' $O$ papel do estado como indutor do crescimento e como articulador da acumulação, foi absolutamente central, no processo, formando um tripé: o Estado, o capital estrangeiro e o capital Nacional'. (NETTO), 2014, p. 41)

Saviani (2008, p. 293), ao analisar esse processo apresenta a preocupação da sociedade brasileira para com a industrialização do país.

[...] em 1960, o modelo havia cumprido suas duas etapas: a primeira, correspondente à substituição dos bens de consumo não-durável (como, por exemplo, as indústrias têxteis e alimentícias), que, por não requerer grandes somas de investimento, foi possível instalar mais rapidamente, com base em capitais nacionais; e a segunda, referente à substituição dos bens de consumo durável (indústrias automobilísticas, eletrônicas, eletrodomésticas), cujas somas vultosas de capitais requereram o concurso das empresas internacionais. Completou-se, assim, o ciclo da substituição das importações: já não dependíamos mais das manufaturas trazidas do exterior. A meta da industrialização havia sido atingida. Logo, não fazia mais sentido lutar por ela. $\mathrm{O}$ que se ocultava sob o objetivo comum (a contradição de interesses) veio à tona quando o objetivo foi alcançado.

Assim quando do golpe, em 31 de março, foi necessário atentar para a forma de encarar o Estado. Estado aquele que segundo os militares tinha em muito perdido seu papel de organizador e disciplinador da sociedade brasileira. Portanto, era preciso substituir, de vez, a ideologia nacional desenvolvimentista pelo desenvolvimento com segurança, mantendo e incrementando o modelo econômico associado ou "subordinado" ao capital estrangeiro.

As bases da nova concepção ideológica encontram -se na Doutrina de Segurança Nacional, desenvolvida na ESG que por sua vez preconizava não só a guerra convencional, mas voltava-se á garantia da segurança interna e as condiçõesa criação de um 'aparato repressivo, encimado por uma rede de informações que permita detectar "o inimigo interno" (os "subversivos"), capaz de neutralizá-lo/eliminá-lo, e a implementação de uma política de desenvolvimento, eficiente e assentada no planejamento para assegurar a força militar do estado.' (NETTO, 2014, p. 87).

A opção foi a ruptura com o processo que alinhava o Estado democrático pela implementação do Estado autocrático, repressor e autoritário. Essa interrupção, causou danos às liberdades democráticas que vinham sendo construídas em conjunto com o Estado 
democrático, no interior da sociedade brasileira, na qual sobressaiam-se os movimentos sociais como principais interlocutores dos trabalhadores e do povo de modo geral.

Ianni (1987:18), ao discutir os processos de rupturas ocorridos no país, os analisa sob a ótica do progresso afirmando que as rupturas podem ser do tipo reformista ou revolucionária.

Ela é revolucionária, ou total, quando altera os fundamentos estruturais da sociedade. Sempre implica a ascensão de uma nova classe ao poder, realizando e simbolizando o rompimento drástico dos vínculos externos e com a sociedade tradicional. A ruptura reformista, por outro lado, ocorre quando se alteram somente certos quadros institucionais, sem qualquer modificação estrutural básica. Implica a ascensão de outras facções da classe dominante ao poder, verificando-se a recomposição das forças políticas e econômicas.

Nesse processo, o novo regime começou a recompor as instituições sociais do país reorganizando a estrutura numa tentativa de desenvolvimento baseada no progresso. A recomposição significou uma nova maneira de governar fez com que os militares abandonassem parcialmente leis do país e aplicassem os chamados os decretos, chamados de Atos Institucionais. Começando pelo Ato número 01, em 09 de abril que na verdade deu "institucionalidade" ao golpe.

CONSIDERANDO que a Revolução Brasileira de 31 de março de 1964 teve, conforme decorre dos Atos com os quais se institucionalizou, fundamentos e propósitos que visavam a dar ao País um regime que, atendendo às exigências de um sistema jurídico e político, assegurasse autêntica ordem democrática, baseada na liberdade, no respeito à dignidade da pessoa humana, no combate à subversão e às ideologias contrárias às tradições de nosso povo, na luta contra a corrupção, buscando, deste modo, "os. meios indispensáveis à obra de reconstrução econômica, financeira, política e moral do Brasil, de maneira a poder enfrentar, de modo direito e imediato, os graves e urgentes problemas de que depende a restauração da ordem interna e do prestígio internacional da nossa pátria" (Preâmbulo do Ato Institucional $\mathrm{n}^{\circ} 1$, de 9 de abril de 1964). Disponível em http://www.planalto.gov.br/ccivil_03/AIT/ait-0568.htm.

É neste cenário que as mudanças educacionais foram realizadas e alteraram significativamente o perfil da educação formal. O governo dos militares ao traçar a linha de condução da política educacional, estabeleceu uma perspectiva que fosse ao encontro das necessidades do momento, ou seja, respeito a nova concepção do poder político recém instalado articulada igualmente uma nova estrutura de dominação.

A partir desse posicionamento, observam-se as mudanças, inclusive no modelo de universidade tendo por base a reforma universitária/ "cujas diretrizes estruturavam a universidade em institutos básicos e escolas ou faculdades (separando o ciclo básico de estudos do ciclo profissional) compostos por departamentos, contratação de professores pela legislação trabalhista; apoio à pós-graduação; autonomia didática para organizar, criar ou extinguir cursos; fixação de critérios para seleção e admissão de alunos" (BOSCHETTI, 2007, p 223). 
A política educacional, adotada, seguia as orientações veiculadas no ideário ditatorial, pautada nas discussões acerca dos caminhos que levavam ao nacionaldesenvolvimentismo; para tanto um conjunto de medidas tomadas pela sociedade política que dizem respeito ao sistema educacional, visando à (re)ordenação das formas de controle social e político. (BARBOSA, 2014).

O Estado sob a tutela dos militares interveio nas instituições sociais com vista a assegurar a dominação política e a manutenção do sistema educacional para os fins pretendidos naquele momento, bem como "atuar de forma a aliviar as tensões e conflitos", (GERMANO, 2005, p. 22. In. SILVA, 2014, p. 131).

A intervenção era necessária porque a educação, desdobrada em ensino formal, é um dos deveres constitucionais do Estado, que deve oferecê-la de forma pública e gratuita. O Estado, ao tratar de sua efetivação, o faz em bases que possam refletir os esforços empreendidos pelo poder político instituído, ao mesmo tempo em que se constitua em uma das estratégias para a manutenção desse poder. Poder este instituído pela força e instalado com sucesso no Brasil.

Por meio da mudança na estrutura do ensino brasileiro especialmente o superior, a intenção era o controle de estudantes e professores, pois a ditadura acreditava, o cerne de resistência encontrava eco nas universidades e neste sentido era importante bloquear os movimentos estudantis, controlar a politização dos estudantes procurando neutralizar a influência dos diretórios acadêmicos sobre as representações estudantis, pois apesar da repressão ainda era grande a ebulição do Movimento estudantil organizado que em alguns episódios contou com apoio popular, como foi no caso da passeata, no Rio de Janeiro quando do assassinato do Estudante Edson Luis ${ }^{4}$ e em Belém quando do também assassinato no interior da UFPA, do aluno Cesar Leite ${ }^{5}$, Em relação a morte deste último, Leite (2015), em texto ao CONSUN-UFPA, relata.

Bem cedo te fizeram calar bem na flor da idade, covardemente, com tiro nas costas estando sentado em sala universitária assistindo aula, na disciplina "Estudos dos problemas Brasileiros", e que problemas... Impuseram o cessar de teus desejos, tua musicalidade, pretensões e aptidões. Nossos pais, em frangalhos. Nossa mãe, hoje com 80 anos ainda anda pelos Tribunais, lúcida.

Boschetti (2007, p 222) analisa a reforma universitária na perspectiva do Programa de Ação Econômica do Governo, o PAEG, a qual sustentou-se com amplo apoio social dos segmentos conservadores.

[...] o projeto da reforma mobilizou a política nacional no período em que foi elaborado o Programa de Ação Econômica do Governo, o PAEG (1964/1966), com rico detalhamento dos projetos do IPES. As reformas apresentaram uma fina sintonia da educação com a ideologia do desenvolvimento com segurança defendida pela coligação de vários grupos: - os conservadores representados pela classe dominante (latifundiários, banqueiros, comerciantes, industriais), segmentos da Igreja Católica e representantes de uma classe média que aspirava conquistas sociais; - a burguesia internacional: atuando na política e na economia brasileiras. 
O poder político é exercido por um grupo comprometido apenas com os setores mais poderosos da classe dominante. Comprometido com esta tanto em seus interesses econômicos como com sua ideologia, sendo que essa ideologia inspira - se nos princípios geopolíticos convenientes aos interesses das corporações multinacionais.

Para atendimento do projeto governamental fez -se necessário promover alterações na estrutura e organização da educação formal, uma vez que os tecnocratas do poder sabiam que para a consecução dos objetivos baseados no princípio de desenvolvimento e segurança nacional, era imprescindível contar com o aparato escolar.

Deste modo, foram realizadas reformas, nos ensinos primário, secundário e superior e afetando o projeto de educação deixando-lhe marcas profundas. Reformas que não contaram com a participação de quem mais interessava, a sociedade. As decisões, obedecendo o padrão do Estado Prussiano, foram tomadas de cima para baixo, orientadas que foram pelos acordos MEC/USAID. Netto (2014, p. 48), ao analisar essa questão diz que o incomodo para com a ampliação da participação popular, incluindo, os sindicatos, organizações estudantis, a exemplo da UNE, Liga camponesa, etc. era de que "os limites de uma democracia restrita estavam sendo forçados, para abrir o passo a uma democracia de participação ampliada - horrorizava as "classes produtoras"

A análise acerca dos fundamentos tecnocráticos e autoritários na política educacional brasileira, implementada pelo governo dos militares tendo por base as reformas de ensino, leis 5.540/68 e 5.692/71, indica-nos que tais fundamentos faziam parte do princípio norteador da política mais geral preconizada pelo novo governo, baseada no desenvolvimento e segurança nacional, na qual observa-se que sob a égide do combate ao comunismo e à corrupção, desencadeou principalmente sob o governo Médici (1969-1974) a maior repressão, prisão, matança e expurgos de políticos e civis de oposição Para tanto, o governo utilizou-se dos aparatos que o poder lhe conferia. Para agir "legalmente", o governo dos militares usou os Atos Institucionais e Suplementares, criou a lei de Imprensa (para controlar a mídia), a Lei de Segurança Nacional e o Serviço Nacional de Informação - SNI.

Seguindo a linha internacional que vivia sob a égide da guerra fria com o mundo dividido em dois blocos: o capitalista, liderado pelos EUA e o Socialista, liderado pela URSS; o país fez coro ao bloco capitalista. Com essa relação, o Brasil passou a sofrer diretamente a influência americana tanto na política quanto na economia, instaurando, um desenvolvimento econômico e estrutural dependente, levando a internacionalização da economia e mantendo o país na periferia do capitalismo mundial.

O governo dos militares implantou um sistema marcado pela burocracia tecnocrática nos aparelhos de Estado, baseados nos princípios de segurança e desenvolvimento; atuaram decisivamente em duas esferas sociais: no aparato econômico e no aparato escolar um refletindo na outro. Como a área econômica constituía-se no eixo fulcral do pensamento tecnocrático foram elas que desencadearam mudanças significativas na educação escolar. O fundamento maior da dinâmica dos "Grandes objetivos", contidos no Programa Estratégico, é a projeção da Educação como o instrumento de maior alcance para a consecução dos objetivos econômicos e sociais da política de desenvolvimento. (Relatório Meira Matos, in Educação em Debate 1968:210).

Seguindo essa linha de raciocínio de adaptar a educação escolar às novas exigências econômicas e político/ideológicas pós-64, a escola brasileira sofreu várias interferências dos militares. As mais significativas foram as Reforma Universitária, leis 5.40/68 e a Reforma de Ensino de $1^{\circ}$ e $2^{\circ}$ Graus, lei 5.692/71, o MOBRAL e a criação da Pós Graduação. 
Tais realizações pautavam - se nos acordos de cooperação entre o MEC e USAID, nos relatórios Aticon de 1966 e Meira Mattos em 1968. A educação transformou - se em assunto de interesse econômico e de segurança. O relatório Meira Matos elaborado em 1968, que propunha medidas saneadoras para os problemas dos estudantes, é altamente emblemático. Isto evidencia que as escolas brasileiras dos 3 graus de ensino foram determinadas pelas altas burocracias do Estado, baseada em três pilares: Educação, Desenvolvimento e Segurança; educação; e, Comunidade.

Com a aprovação da Lei 5540/68 o governo cerceou a liberdade de produção científica nas universidades quando por meio de tais mudanças institucionais legais e aleatórias, limitou alunos e docentes quanto a suas práticas na condição de pesquisadores e podemos afirmar que nas universidades não havia assegurado nem mesmo o direito a discutir ideias em simples conversas informais se estas não estivessem de acordo com o ideal capitalista.

Em relação ao decreto 477, Germano (2011, p.68), afirma:

A escalada repressiva do governo, por sua vez, disseminava-se por toda a sociedade, feria de morte a liberdade de expressão ao instituir a censura prévia à imprensa e ao ampliar o controle político- ideológico das universidades e demais instituições educativas, mediante a ação do Decreto lei 477 de fevereiro de 1969.

Sob a legalidade do Decreto Lei 477, começou o período de prisões de alunos e professores dentro das universidades e debaixo do Ato Institucional Número $5^{6}$ que foi decretado duas semanas após a aprovação da Lei 5540/68, se inicia o tempo de maior repressão no Brasil:

[...] Como AI-5, de dezembro de 1968, e se estende por todo o governo Médici (1964-1974). Nesse período o Estado tentou sufocar a sociedade civil, notadamente os segmentos que lhe faziam oposição, com os estudantes, os intelectuais e os trabalhadores. (Germano 2011, p. 94)

Deste modo, a educação superior, assumiu características tecnocráticas e autoritária, porque foi direcionada apenas para o desenvolvimento econômico e ideológico mantendo o poder instituído pela força. Neste cenário o ensino era tido como um problema técnico a ser resolvido pelo aparelho estatal competente para adequar sua finalidade ao bom funcionamento da estrutura e resultados de qualquer empresa.

Esse caráter adotado pelo ensino era o que preconizava o Relatório Meira Matos, a estrutura empresarial deve oferecer uma organicidade lógica, criando escalões sucessivos de direção técnica e de administração, tudo no sentido de assegurar a fluição natural das ordens e diretrizes, a sua apreciação por setores, a coordenação administrativa e técnica e o fácil trânsito vertical de cima para baixo e de baixo para cima. (Relatório Meira Matos, in Educação em Debate 1968, p. 211).

Neste sentido, o ensino superior seguiu o modelo de modernização (EUA). Os militares tinham todo interesse em modernizar o ensino superior tendo em vista o desenvolvimento científico - tecnológico tão necessário aos seus interesses tanto do ponto de vista interno como externo. A reforma universitária de 1968, realizada sob os auspícios do Ato Institucional número 5 e decreto 477, preconizava o ensino como um processo que levasse em conta o quantitativo e a otimização de investimentos; a administração do sistema universitário baseada nas grandes empresas; recondução das escolas superiores 
administrativas e disciplinar e; condenação da autonomia universitária. Seguindo essa lógica, a RU implementou: o departamento; a matrícula por disciplina; o ciclo básico; o vestibular unificado e classificatório e institucionalizou a pós - graduação.

No geral o que prevaleceu foi a orientação da teoria geral de administração de empresas pois seguiu os passos dos relatórios americanos associados a tecnoburocracia social e militar. Em relação aos ensinos primário e secundário, a idéia era de consolidação da idéia de educação como custo - benefício, logo, o ensino teria que ser subordinado ao mercado de trabalho.

A lei 5.692/71 transformou, compulsoriamente, o ensino de $1^{\circ}$ e $2^{\circ}$ Graus em ensino técnico profissionalizante, deixando um legado histórico/pedagógico difícil de ser esquecido. Em seus objetivos apregoa:

Art. $1^{\circ} \mathrm{O}$ ensino de $1^{\circ}$ e $2^{\circ}$ graus tem por objetivo geral proporcionar ao educando a formação necessária ao desenvolvimento de suas potencialidades como elemento de auto-realização, qualificação para o trabalho e preparo para o exercício consciente da cidadania. Disponível em $\quad$ http://presrepublica.jusbrasil.com.br/legislacao/128525/lei-dediretrizes-e-base-de-1971-lei-5692-71.

Saviani (2008, p. 298) ao analisar a referida lei faz um alerta importante.'a Lei n. 5.692/71, que unificou o antigo primário com o antigo ginásio, criando o curso de $1^{\circ}$ grau de 8 anos e instituiu a profissionalização universal e compulsória no ensino de $2^{\circ}$ grau, visando atender à formação de mão-de-obra qualificada para o mercado de trabalho.' (SAVIANI, 2008, p. 298), ou seja, a formação da cidadania subsumiu à qualificação da mão de obra ao mercado de trabalho, pois como tratar de formação para cidadania, tendo a cidadania negada?

Segundo Germano (2008, p. 324), o país vivia a euforia desenvolvimentista. Os militares pretendiam colocar o Brasil em ordem, por isso reformaram instituições conforme a sua visão estratégica de progresso, simbolizada pela ideia de Brasil/potência. Portanto, a reforma do Ensino de $1^{\circ}$ e $2^{\circ}$ graus, por sua vez, pretendeu atingir um duplo objetivo, sem descuidar do projeto de cidadania pensado para este período, qual seja: de um lado, conter a crescente demanda sobre o ensino superior; de outro, promover a profissionalização de nível médio. (Silva, 2014, p.131).

A reforma foi aprovada no apogeu do milagre econômico e dos anos de "chumbo" do regime. A Lei não alterou de todo a 4.024/61, incorporou aos fins desta os objetivos do novo ensino, isto é, auto formação, qualificação para o trabalho e exercício consciente da cidadania.

Ao se analisar os fundamentos em que a reforma se baseia observa - se que esta visava o fornecimento de mão - de - obra barata às empresas, e também a criação de um exército de reserva de profissionais "baratos." Além disso, as escolas passaram a ser estruturadas e organizadas como empresas burocratizadas. Desse modo, a escola reproduz o capital, isso era necessário porque a partir de 1964, o país passou a viver sob a égide da "modernização" da sociedade política como consumo industrial das massas.

Necessariamente essa "modernização" da sociedade política implica tanto num tipo de reorganização administrativa, tecnológica e financeira, como também na organização de mecanismos de exceção que garantem o controle social e político correspondente aos pressupostos da modernização. (Oliveira, 1981:73/74).

Essa preocupação é também verificada no Relatório Meira Matos de 1968. (...) tal política deverá basear - se em uma pesquisa realista do mercado, o que implica em uma 
visualização das peculiaridades regionais, para verificação de suas necessidades mais prementes, tudo visando a um quadro das necessidades globais do país e das prioridades que daí devem decorrer. (Relatório Meira Matos, in Educação em Debate 1968:222).

Além do mais a transformação da escola em empresa e a implantação gradual da reforma era fundamental no projeto MEC/USAID. A relação da educação e segurança, que dizia formar cidadão consciente, possibilitou a introdução das disciplinas Educação Moral e Cívica, Organização social e Política do Brasil e Educação e Problemas Brasileiros. A introdução da disciplina sobre civismo significa imposição da ideologia da ditadura desenvolvimento e segurança nacional.

A lei preconizava a sua aplicação em todo o território nacional, havendo uma centralização da educação formal. Entretanto, a falta de recursos humano e material aliado ao desejo do lucro desmedido, permite pensar que os cursos supostamente profissionalizantes, não profissionalizaram àqueles que de fato buscam no aparelho escolar possibilidade de formação técnico/profissional, alunos oriundos das camadas populares.

Com a expansão do número de escolas de primeiro grau e a introdução de "estudos sociais" no currículo acabou faltando professor. Para suprir esta necessidade criou-se as licenciaturas curtas. Os cursos de licenciatura curta que preconizavam à formação de professores em, em todos os cantos do país; foram oferecidos majoritariamente pelas faculdades particulares que obtiveram grandes lucros, formando em contrapartida uma mão de obra barata e intelectualmente mal formada.

Visava essa medida permitir uma formação curta de professores para as zonas carentes, onde a necessidade de professoras/es com qualificação exigida por lei era/é um problema histórico. Apoiados nessa "abertura legal", difundiram-se cursos com o propósito apenas de obter lucros, desde que houvesse número suficiente de alunos que pudessem pagar anuidades vultosas. (Werebe, 1994: 204).

A reforma de ensino de $1^{\circ}$ e $2^{\circ}$ Graus é a exaltação da razão burocrática, ou seja, a destruição da reflexão crítica em nome da racionalidade reduzida a integração e ordenação, encobertos pelo problema neutralidade pelas idéias de eficiência e produtividade numa administração e planejamento despolitizado, acaba difundindo uma ideologia de sociedade homogênea e harmônica; visa portanto, adaptar o indivíduo à sociedade e fortalecer as estruturas de poder vigente na ditadura.

A extensão da obrigatoriedade do ensino de 4 para 8 anos e formação de professores são pontos marcantes, importantes e considerados com avanços para o fortalecimento da qualidade do ensino. Em relação a obrigatoriedade, ressalta-se que nem os chamados governos democráticos implementaram. Logo essa revisão permitiu que fosse atingido um número bem maior de alunos em idade escolar, pela lei, dos 7 aos 14 anos. Mas esse atendimento por si só não resolveu o problema da educação básica brasileira, ao contrário, o problemas foram aprofundados, especialmente aqueles relacionados a percepção democrática e ao direito a educação.

No ensino de $2^{\circ}$ grau, técnico/profissionalizante com caráter de terminalidade não obteve o êxito nem qualificou os jovens das camadas populares, estabelecendo uma maior desigualdade entre pobres e ricos. Estes últimos, buscaram abrigo na s escolas particulares para prepararem-se e ingressarem nas universidades melhores, ou seja nas públicas.

A lei $n^{\circ} 5692 / 71$ completa o ciclo de reformas educacionais geradas com o intuito de efetuar o ajustamento necessário da educação nacional à ruptura política orquestrada pelo movimento de 1964.

Finalmente a análise da política educacional dos governos dos militares, alerta para o fato de que os tecnocratas pretenderam modificar a educação formal baseados na teoria do capital humano, insistiram na tese da "educação como investimento", ou "investimento 
nos recursos humanos" e desta forma, cada homem e cada mulher poderia produzir mais e melhor contribuindo com sua formação para o projeto em curso sob os auspícios do desenvolvimento econômico do País, livre do fantasma do comunismo.

Por outro lado, observa - se que 'a instituição de uma ditadura que durou 21 anos e que pôs termo ás liberdades democráticas, estabelecendo no país um regime de violenta repressão e arbitrariedades'. Werebe (1994:75) contribui sobremaneira para aprofundar as desigualdades sociais e educacionais, criando com isso uma escola que em muito distanciou-se dos anseios das classes populares.

Hoje, quando o Estado brasileiro vive e experimenta a democracia, ainda que com fragilidade, exigida por singular momento de reorganização social tendo em vista a o golpe que tirou da presidência uma presidenta, oriundo da luta armada sob o escopo da derrocada do regime militar, sobretudo porque a classe dominante e reacionária não aceitava de bom grado, a decisão soberana do povo brasileiro representado pelo voto em processo de (re)eleição, obriga o país a repensar as suas políticas sociais em particular as políticas sociais educacionais.

Nesta linha de raciocínio, considera -se de suma importância a análise e a discussão de reformas ocorridas na estrutural educacional brasileira, durante a ditadura. Delas pode se tirar lições que nos apontem o desenvolvimento da humanidade em busca de melhor qualidade de vida. É neste propósito que o estudo dos fundamentos tecnocrático e autoritário na política educacional brasileira implementada pelos militares, $1964-1985$ se apresenta.

\section{Referências Bibliográficas}

BOSCHETTI, Vania Regina. Plano Atcon E Comissão Meira Mattos: Construção D0 Ideário Da Universidade Do Pós-64. Revista HISTEDBR On-line, Campinas, $\mathrm{n}^{\circ} .27$,

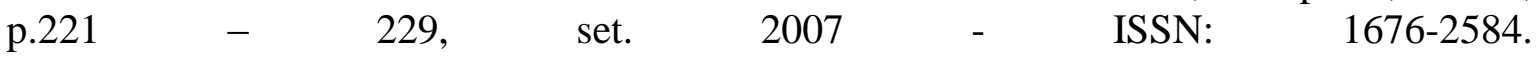
http://www.histedbr.fe.unicamp.br/revista/edicoes/27/art18_27.pdf. $\quad$ Acesso em 15/06/2015, às 10:48h.

BRASIL. Ato Institucional $\mathrm{N}^{\circ}$ 5, de 13 de Dezembro de 1968. Disponível em http://www.planalto.gov.br/ccivil_03/AIT/ait-05-68.htm. Acesso em 23/06/14, às 15:19h.

BRASIL. Lei 5.692 de 11 de agosto de 1971. Disponível em: http://presrepublica.jusbrasil.com.br/legislacao/128525/lei-de-diretrizes-e-base-de-1971lei-5692-71. Acesso em 18/09/15, às 22:34h

CHAUI, Marilena Sousa. Ventos do progresso: A universidade Administrada. In Descaminhos da Educação pós 68. São Paulo: brasiliense, 1980

GASPARI, Elio. A ditadura envergonhada. São Paulo: Companhia das Letras 2002.

http://presrepublica.jusbrasil.com.br/legislacao/128525/lei-de-diretrizes-e-base-de-1971lei-5692-71

GHIRALDELLI, Paulo, Júnior. História da Educação. São Paulo: Cortez, 2000

GOVERNO DE ESTADO DE SÃO PAULO. Diretrizes e Bases para o Ensino de $1^{\circ}$ e $2^{\circ}$ Graus. São Paulo: Edição especial, 1971.

http://www4.planalto.gov.br/legislacao/legislacao-historica/atos-institucionais. Acesso em 4/04/15, às 12:19h.

IANNI, Otávio. O colapso do populismo no Brasil. Rio de Janeiro: Editora civilização brasileira, 1987.

NETTO, José Paulo. Pequena história da ditadura brasileira (1964-1985). São paulo OLIVEIRA, Betty Antunes de. O Estado autoritário brasileiro e o ensino superior. São Paulo; Cortez, 1981

RELATÓRIO MEIRA MATOS. In Educação em debate, nº 09, São Paulo, 1968. 
ROSÁRIO, Maria José Avizdo. O Pcb E A Organização Do Ensino Público Primário

De Belém Do Pará (1945 A 1964). Tese de doutoramento. Universidade Federal de São Carlos - UFSCAR: Belém- Pará, 2006.

SYRKIS, Alfredo. Os carbonários: memórias da guerrilha perdida. São Paulo: Globo Editora e Distribuidora Ltda., 1980.

SAVIANI, Dermeval. O Legado Educacional Do Regime Militar. Cad. Cedes, Campinas, vol. 28, n. 76, p. 291-312, set./dez. 2008. Disponível em http://www.scielo.br/pdf/ccedes/v28n76/a02v2876.pdf. Acesso em 04/09/14, às 14:56h

SILVA, Rosângela Maria de Nazaré Barbosa. A EDUCAÇÃO BÁSICA NO ESTADO DO PARÁ (1970-1985). Tese de doutoramento. Universidade Federal do Pará - PPGEDUFPA, Belém- Pará, 2014.

WEREBE, Maria José Garcia. Grandeza e misérias do ensino no Brasil. São Paulo: ática, 1994.

\section{Notas}

\footnotetext{
${ }^{1}$ Professora da Universidade Federal do Pará - UFPA

${ }^{2}$ Evento do Programa de Pós - Graduação da Universidade Nove de Julho - UNINOVE - São Paulo. http://www.uninove.br/PublishingImages/Mestrados\%20e\%20Doutorados/edu/I\%20seminario/MFE\%207.pd $\frac{\mathrm{f}}{3}$

${ }^{\frac{1}{3}}$ Ver análises sobre as principais motivações ao Golpe em, NETTO (2014).

${ }^{4}$ Foi assassinado no interior do restaurante Calabouço-Rio de Janeiro.

${ }^{5}$ Morto por uma bala enquanto assistia aula, no bloco B, do Campus Básico da UFPA.

${ }^{6} \mathrm{O}$ AI-5, editado em 13 de dezembro de 1968, reeditou os princípios do AI-1, suspendeu o princípio do habeas corpus e instituiu, de forma clara e objetiva, a tortura e a violência física contra os opositores do regime. Na verdade o AI-5 simbolizou um terceiro ciclo de repressão. O primeiro ciclo foi originado em meio à turbulência do golpe de 1964 e teve, como base, principalmente, a retirada do âmbito político de pessoas vinculadas ao governo deposto de João Goulart. Fisicamente, a repressão recaía apenas sobre os trabalhadores e camponeses que, aosolhos dos militares, poderiam acabar desenvolvendo um foco de combate e resistência contra o governo oficial. (Brasil, 1968)
}

Recebido: novembro/16 Aprovado: dezembro/16 